\title{
International Symposium "Cultivation of marine organisms and its importance for marine biology": Closing address
}

\author{
O. KINNE \\ Biologische Anstalt Helgoland (Zentrale); Hamburg 50, Germany (FRG)
}

Ladies and Gentleman, dear Colleagues and Friends!

The International Helgoland Symposium 1969 on Cultivation of marine organisms and its importance for marine biology has come to an end. What remains to be done is to thank all of you most cordially for coming here and for participating in this meeting. I would like to express my special gratitude to all chairmen and speakers, the contributors to the discussions, and, of course, to the two conveners, Dr. R. J. Conover and Dr. G. Hempel, who have both been very successful in initiating and guiding the informal discussions along well considered lines of thought. I do hope that both of them will present us with an edited, abbreviated version of the informal discussions and that these summarized contributions may inspire future research".

As in the preceding International Symposia sponsored by our Institution, I have been assisted by several of my colleagues from the Biologische Anstalt Helgoland. Again, they have done their utmost to help to organise this Symposium and to solve various problems, which - frequently unpredictable - are inseparably associated with the organization of such meetings.

I am especially indebted to Dr. W. KRumbern who has helped most capably with the local organization and who has worked out the details of the "Dünen Party" which - I have been told by several participants - is likely to enter the long list of legendary tales regarding social happenings, circulating among marine biologists.

I would also like to thank my secretaries, Frau G. Wurl, Miss V. Clark and Fräulein H. WITt, and our administration, especially Herr P. BradHERING and Frau A. HEINEMANN, as well as the many other members of this Institution who made their services available.

During the last $3 \frac{1}{2}$ days we have listened to 64 formal papers and subsequent

* We intend to publish the reports by Drs. R. J. Conover and G. Hemper in Volume 21 of Helgoländer wissenschafliche Meeresuntersuchungen. 
discussions, and we have discussed in depth special aspects of maricultural research both from ecological and economic perspectives.

The Symposium has revealed that the basic terminology of cultivation research is ambiguous and, hence, requires qualification. We may distinguish four aspects of cultivation:

Maintenance - keeping alive of organisms, without significant growth, for scientific or commercial purposes.

Raising - bringing up (fattening) of young adults.

Rearing - bringing up of early ontogenetic stages (e. g. fertilized eggs, larvae).

Breeding - production and bringing up of offspring.

In these definitions, raising includes maintenance, rearing includes maintenance and raising, and breeding includes maintenance, raising and rearing. Farming of marine organisms is based on raising, rearing and/or breeding. Stock improvement, domestication and production of defined strains or populations require genetic recombination, i. e. breeding under controlled conditions. The term "aquaculture" refers to cultivation of aquatic organisms, the term "mariculture" to cultivation of marine organisms.

It is certainly too early to attempt a detailed assessment of the information presented and discussed, and of the potential influence which this exchange of ideas may exert on future research concerned with marine cultivation. However, it seems appropriate to list a few points:

(1) The Symposium participants contributed to the general topic from a wide variety of viewpoints stressing the interdisciplinary aspects in cultivation research and the need for international co-operation. Marine microbiologists, botanists and zoologists have outlined their respective problems, procedures, and results, ranging from small-scale laboratory experiments largely devoted to basic research, to full-scale production of marine organisms in considerable quantities for commercial use. They have considered all aspects of cultivation: maintenance, raising, rearing and breeding.

(2) Cultivation of marine organisms is about to enter a new phase of activity and growth. The need for more pertinent knowledge both in basic and applied research is all too obvious. Modern methods have given new impetus to our thoughts and concepts. It does not seem too optimistic to predict that we may expect significant advances in the field of marine cultivation and experimentation within the present decade.

(3) There is considerable demand for developing new aquacultural technologies. While it has been possible to improve centuries old cultivation techniques of economic algae, mollusc, crustacean, and fish farming, we need a fresh assessment of the most important goals and to make full use of modern technical means.

(4) Particular difficulties have to be overcome with regard to cultivation of planktonic organisms, especially of oceanic zooplankton. But even here, breakthroughs are sight (e. g. planktonkreisel [p. 305], phytoplanktonkreisel [p. 308], trichterkreisel [p. 687]).

(5) We must do more work on simple experimental ecosystems. In nature, no species exists by itself. It seems of utmost importance to study the rates of transfer of energy and matter in multispecies cultures in order to be able to achieve maximum 
comprehension of the complex dynamics of natural assemblages of marine organisms. Microbiologists, botanists and zoologists must work here hand in hand.

(6) A single investigator becomes less and less able to deal with multidimensional aspects. While the initiative of single individuals will remain an unabandonable source of stimulation, motivation and inspiration, in practice, more and more problems can only be tackled sufficiently and adequately by teams of scientists and technicians - teams in which a broad spectrum of talents and experiences are represented.

(7) In regard to economical aquaculture, raising, rearing, breeding and harvesting procedures must be mechanized to a greater extent in order to produce more efficiently; the same applies to stock improvement, feeding and disease control. Most of the few marine molluscs, crustaceans and fishes hitherto cultivated on a commercial scale are still considered to be delicacies. They are expensive and can be afforded only by few people. It must be our aim to reduce production costs if we want to improve the diets of all people. Only in this way can we hope to make a sound contribution toward solving the present food crisis.

(8) The basic prerequisite for large scale scientific and commercial out-door mariculture is a healthy marine environment. Water pollution and aquaculture are, therefore, two aspects of human activities which tend to be incompatible.

(9) Domestication of marine organisms suitable for commercial mariculture requires more knowledge on population genetics, nutrition and food conversion efficiency.

(10) Studies on nutritional requirements indicate that proper energy sources (chemical composition of food, its physical properties such as compactness, solidity, particle size and density, digestibility), absence of toxins, presence of vitamins, growth promoting substances, and trace elements are most important - but hitherto often neglected - aspects for successful cultivation. Different life-cycle stages of a marine animal may need different food sources; only rarely do members of a single prey species satisfy all energy requirements. Continuous cultivation over many generations necessitates a perfect match of food source properties and predator requirements; otherwise, increased mortality, reduced final body size, low fertility and impotence may intervene (e.g. p. 445).

(11) Possibly, a number of marine organisms can be cultivated at reasonable cost only in assemblages in which 2 or more culture partners provide mutually the basic prerequisites for their continued existence (balanced microcosm; biosystem).

(12) Farming of marine and brackish water organisms for commercial ends will become an increasingly important pursuit for modern mankind. Its primary object is the management and utilization of renewable biological resources. Its future lies in coastal waters such as bays and estuaries, rather than in the open sea.

An important problem of cultivating marine organisms for experimental purposes is to have defined strains or populations of marine organisms with comparable genetic and environmental backgrounds available for distribution to interested experimenters or institutions. Dr. H. J. HUEck of the Centraal Labatorium TNO in Delft, The Netherlands, has submitted to me an interesting proposal which I would like to read to you. Dr. Hutck writes:

"In microbiology a good organization of culture collections exists where strains 
of bacteria, fungi and algae can be obtained. Entomologists desirous to have the same facilities found a solution by instituting an information service on insect strains, available to laboratories all over the world. Scientists partaking in this co-operative effort and wishing to obtain a certain insect strain for their experiments can easily locate a source for such a strain by looking up the index of the mimeographed directory issued to all members. The 'Insect Toxicologists Information Service' is organized by the Laboratory for Insect Toxicology in Wageningen, The Netherlands. It is issued free to participants and has the benefit of some international subventions.

I wonder whether such a service would not be of benefit to marine biologists too. If participants of this International Symposium feel that such a service would be helpful in their efforts, my laboratory can offer to organize the compilation of a first bulletin by circulating a questionnaire, by organizing and indexing the answers and by issuing a (simple) bulletin free to all participating laboratories. For an improved second edition the experience thus gathered might be considered by some appropriate international body."

So much for Dr. HuEck's proposal. I would like to support it wholeheartedly. Anybody interested in this proposal should write to Dr. Hueck; his full address can be found in the List of Participants.

In general, it appears that this International Symposium has been a useful platform for assessing our present body of knowledge on mariculture and for stimulating new research in this important field of marine biology.

One point which is not immediately related to the scientific aspects of this Symposium but which, nevertheless, deserves mentioning is the aspect of human understanding and co-operation across existing barriers of national, philosophical, religious or other engagements. Personally, I am deeply devoted to promoting such "finding together" of individuals with different conceptual backgrounds. It was one of the most rewarding experiences for me during this meeting to see how much everybody enjoyed disregarding the various, often rather artificial barriers, and to get reduced to what he actually is: a human being among his kind, devoted to helping to solve scientific problems for the benefit of the whole human population on this earth!

For a few of us the Symposium is not yet over and will not be for some time to come. Dr. H.-P. BuLNHEIM, my secretaries and I are some of these persons. We shall now be busy for several months editing and publishing the contributions to this meeting. We look forward to these post-Symposium activities with a well-balanced mixture of excitement, interest, and - horror! We shall make every effort to publish the proceedings of this meeting within 7 or 8 months. Please help us! You can help us by submitting your manuscripts, ready for publication, and prepared according to the "Instructions for Authors" given to you, by attending immediately to editorial inquiries, and by sending back your proofs by return mail.

With this plea for further co-operation to achieve fast publication of the proceedings, I would like to close. Thanks again to all of you and a good trip home!

I herewith close the International Helgoland Symposium 1969 on Cultivation of marine organisms and its importance for marine biology. 